\title{
STING Mediates Cytosolic Dna-Induced Muc5ac Mrna Expression in Human Bronchial Epithelial Cells
}

\section{Masaya Ohta}

Nihon Shika Daigaku Niigata Seimei Shigakubu Daigakuin Niigata Seimei Shigakubu Kenkyuka

\section{Yutaka Nishida}

Gunma University Graduate School of Medicine

Hisako Yagi

Gunma University Graduate School of Medicine

\section{Aikira Aizawa}

Gunma University Graduate School of Medicine

\section{Takahito Oyanagi}

Niigata University Graduate School of Medical and Dental Sciences

\section{Akihiko Saitoh}

Niigata University Graduate School of Medical and Dental Sciences

\section{Satoshi Yamada}

Gunma University Graduate School of Medicine

\section{Takashi Ishige}

Gunma University Graduate School of Medicine

Yasuko Kobayashi

Gunma University Graduate School of Medicine Hirokzu Arakawa

Gunma University Graduate School of Medicine

Takumi Takizawa ( $\nabla$ takizawt@gunma-u.ac.jp )

Gunma University https://orcid.org/0000-0003-2169-0787

\section{Research}

Keywords: cytosol, epithelial cells, immunity, lung, mucins

Posted Date: June 29th, 2020

DOI: https://doi.org/10.21203/rs.3.rs-37814/v1 
License: (c) (i) This work is licensed under a Creative Commons Attribution 4.0 International License. Read Full License 
5 Saitoh $^{2}$, Satoshi Yamada ${ }^{1}$, Takashi Ishige ${ }^{1}$, Yasuko Kobayashi ${ }^{1}$, Hirokazu Arakawa ${ }^{1}$, Takumi

6 Takizawa $^{1 *}$

$7 \quad{ }^{1}$ Gunma University Graduate School of Medicine, Department of Pediatrics

${ }^{2}$ Niigata University Graduate School of Medical and Dental Sciences, Department of Pediatrics

*Corresponding author

3-39-22 Showa-machi, Maebashi, Gunma, 371-8511, Japan

Phone: +81-27-220-8203; Fax: +81-27-220-8216; Email: takizawt@gunma-u.ac.jp_(TT)

Short title: STING mediates $M U C 5 A C$ expression

\begin{abstract}
Background: Non-autologous and autologous cytosolic DNA are recognized as danger signals by cytoplasmic sensor molecules that activate signal-transduction pathways. An important molecule in cytosolic DNA sensing is stimulator of interferon genes (STING), an endoplasmic reticulum protein activated by cyclic GMP-AMP (cGAMP) produced in response to cytosolic DNA. STING is important for innate immune responses to cytosolic DNA in immune cells; however, knowledge about its role in bronchial epithelial cells is limited.
\end{abstract}


Methods: We stimulated NCI-H292 cells with poly(dA:dT) and silenced STING and other regulatory proteins, and then determined $M U C 5 A C$ mRNA expression levels.

Results: Cytosolic DNA increased the expression of a major respiratory mucin protein, MUC5AC, in the human respiratory epithelial cell line NCI-H292 in a STING-dependent manner. Introducing poly $(\mathrm{dA}: \mathrm{dT})$ into the cytoplasm induced $M U C 5 A C$ and interferon- $\beta$ (IFN $\beta$ ) expression. Silencing STING by RNA interference decreased poly(dA:dT)-induced MUC5AC mRNA expression but increased $I F N-\beta$ mRNA levels. Furthermore, cGAMP treatment increased MUC5AC expression but not $I F N-\beta$ expression. In contrast, silencing retinoic acid-inducible gene-I $(R I G-I)$, which is a component of a different nucleic acid-sensing system, suppressed poly(dA:dT)-induced $I F N-\beta$ expression and increased $M U C 5 A C$ expression.

Conclusions: Unlike its role in other cell types, in human bronchial epithelial cells, STING is central to cytosolic DNA-induced MUC5AC expression, whereas $I F N-\beta$ expression is dependent on RIG-I. Our data indicate a functional interaction between the STING and RIG-I pathways, suggesting the existence of intricate and cell-specific cytosolic DNA-sensing systems.

Keywords: cytosol, epithelial cells, immunity, lung, mucins

\section{Introduction}

Mucus secretion plays a pivotal role in eliminating pathogens from the airway epithelium [1]. MUC5AC, a representative mucin protein in the airways, is primarily secreted from goblet cells [2]. Although MUC5AC deficiency does not affect the clearance of bacteria in mice, its overexpression increases clearance [3], indicating that its secretion into the airways is protective. $M U C 5 A C$ production is upregulated during lung inflammation caused by multiple disorders, including asthma and airway infections [4]. Proinflammatory cytokines, including IL- 
4, IL-13, and transforming growth factor (TGF)- $\alpha$, can induce $M U C 5 A C$ expression [5], as can external agents such as cigarette smoke and virulent microorganisms [6].

Microorganisms trigger immune responses through pathogen-associated molecular patterns that are sensed by pattern-recognition receptors (PRRs) of host innate immune systems $[7,8]$. An example of PRRs are the TLRs; the double-stranded poly(I:C) is a ligand for TLR3 that enhances MUC5AC expression at both the mRNA and protein levels [5]. In addition to TLRs, other PRRs for cytosolic RNA or DNA have been identified, including DEAD box polypeptide 41 [9], RNA polymerase (RNAP) III, retinoic acid-inducible gene-I (RIG-I), DNAdependent activator of IFN-regulatory factors, and absent in melanoma 2 [10, 11]. Cytosolic DNA, derived from genomes (both nuclear and mitochondrial) and pathogenic microorganisms, is sensed as a danger signal, which activates innate immunity through these cytosolic DNA- and RNA-sensing mechanisms $[12,13]$. Stimulator of interferon genes (STING) is an endoplasmic reticulum protein involved in cytosolic nucleic acid-sensing systems. It was first identified as a critical mediator of the production of proinflammatory cytokines, including type-I IFNs, in response to viral DNA [14]. STING is activated by cyclic GMP-AMP (cGAMP) produced by cGAMP synthase (cGAS), which senses cytosolic DNA [15]. STING has been implicated in innate immune responses to cytosolic DNA in multiple cell types $[16,17]$. However, little is known about its role in bronchial epithelial cells, which are responsible for front-line pathogen defenses in the lungs. We investigated the role of STING in MUC5AC expression and unexpectedly found that STING and RIG-I serve different roles in human bronchial epithelial cells. Our results provide insights into the understanding of lung homeostasis and inflammation.

\section{Methods}




\section{Cell culture and reagents}

The human pulmonary mucoepidermoid carcinoma cell line NCI-H292 (ATCC CRL1848) was maintained in RPMI 1640 medium (Thermo Fisher Scientific, Waltham, MA, USA) supplemented with $10 \%$ fetal bovine serum (FBS), penicillin $(100 \mathrm{U} / \mathrm{mL})$, and streptomycin (100 $\mu \mathrm{g} / \mathrm{mL})$ at $37^{\circ} \mathrm{C}$ in a humidified atmosphere with $5 \%(\mathrm{v} / \mathrm{v}) \mathrm{CO}_{2}$. The NCI-H292 cells were expanded in 24-well plates and maintained in serum-free RPMI 1640 medium for $6 \mathrm{~h}$ before stimulation with mithramycin A (Cayman Chemical, Ann Arbor, MI, USA) for 30 min or with ML-60218 (Cayman Chemical) for $2 \mathrm{~h}$. Subsequently, the cells were transfected with $0.5 \mu \mathrm{g}$ of poly(dA:dT; Thermo Fisher Scientific) using polyethylenimine MAX (Polysciences, Warrington, FL, USA) and incubated for $6 \mathrm{~h}$. The transfected cells were subsequently exposed to $25 \mu \mathrm{g} / \mathrm{mL}$ poly(I: C; Sigma-Aldrich, St. Louis, MO, USA) and 4 ng/mL TGF- $\alpha$ (R\&D Systems, Minneapolis, MN, USA) for $6 \mathrm{~h}$ at $37^{\circ} \mathrm{C}$. For plasmid stimulation, the cells were transfected with $0.5 \mu \mathrm{g}$ of pcDNA6.2-EGFP in 24-well plates, using FuGENE HD (Promega, Madison, WI, USA). For cGAMP (Thermo Fisher Scientific)-mediated cellular stimulation, cells were incubated in the presence of cGAMP for $16 \mathrm{~h}$.

\section{Gene knockdowns}

For the gene-silencing experiments, we used small interfering RNAs (siRNAs) against STING, RIG-I, interferon regulatory factor 3 (IRF3), RELA, tripartite motif protein 32 (TRIM32), tripartite motif protein 56 (TRIM56) (Thermo Fisher Scientific), and DExH-box helicase 29 (DHX29) (Dharmacon, Inc., Lafayette, LA, USA) mRNAs, together with a control scrambled siRNA. Before transfection, NCI-H292 cells were seeded into $24-$ well plates and grown to $60 \%$ confluence. The cells were incubated in $500 \mu \mathrm{L}$ of antibiotic-free RPMI 1640 medium 
supplemented with 10\% FBS. Then, a mixture comprised $100 \mu \mathrm{L}$ Opti-MEM (Thermo Fisher Scientific), $2.5 \mu \mathrm{L} 20 \mu \mathrm{M}$ siRNA for $D H X 29$ or $1.2 \mu \mathrm{L} 5 \mu \mathrm{M}$ siRNA for the remaining genes, and $1 \mu \mathrm{L}$ Lipofectamine RNAiMAX Reagent (Thermo Fisher Scientific) was added to each well, followed by incubation for another $6 \mathrm{~h}$. The medium was then changed to $500 \mu \mathrm{L}$ RPMI supplemented with $10 \%$ FBS and antibiotics. After $18 \mathrm{~h}$, the cells were stimulated.

\section{Reverse transcription (RT)-PCR and real-time quantitative PCR (qPCR) experiments} Total RNA was isolated using the ToTally RNA Kit (Thermo Fisher Scientific). RT was performed with $500 \mathrm{ng}$ total RNA and oligo(dT) primers, using SuperScript III (Thermo Fisher Scientific). qPCR was performed with either KAPA SYBR FAST qPCR Master Mix (Roche) or TaqMan gene-expression assays (Thermo Fisher Scientific), using the ABI Prism 7900HT sequence detection system. TaqMan assays were used to detect MUC5AC (HS01365601_m1) and $18 \operatorname{SrRNA}$ (4319413E). The sequences of the other primers used for the SYBR Green assays are shown in Supplementary Table 1. Gene-expression levels were normalized to 18S rRNA expression, and fold changes were calculated.

\section{Statistical analyses}

All data are expressed as the mean \pm standard error of the mean. The results were analyzed using analysis of variance, followed by a post-hoc Tukey test or Dunnett test. Analyses were performed with SPSS statistics software version 24 (IBM). A $P$ value of less than 0.05 was considered to reflect a statistically significant difference. 


\section{Results}

\section{Cytosolic DNA induced $M U C 5 A C$ and IFNB1 mRNA expression}

Because cytosolic DNA evokes a primary immune response in immune cells [18] and mucin production participates in the primary immune response in bronchial epithelial cells [1], we analyzed whether cytosolic DNA could induce mucin production in bronchial epithelial cells. We transfected H292 respiratory epithelial cells with plasmid DNA, pcDNA6.2-EGFP, and measured the expression of $M U C 5 A C$ mRNA. The plasmid DNA increased $M U C 5 A C$ mRNA expression only in the presence of a lipofection reagent (Fig. 1a), which indicated that the plasmid DNA needed to enter the cells to induce $M U C 5 A C$ expression. The $M U C 5 A C$ expression levels were comparable to that induced by synergistic stimulation with poly(I:C) and TGF- $\alpha[19-21]^{19-21}$.

Non-methylated $\mathrm{CpG}$ present in bacterial DNA can induce a host immune response after binding with TLR9 $[22,23]$. We used a synthetic double-stranded DNA, poly(dA:dT), to determine whether plasmid DNA-induced $M U C 5 A C$ expression requires non-methylated CpG. Transfecting poly(dA:dT) increased MUC5AC expression with approximately 5-fold greater efficiency than did transfecting a plasmid (Fig. 1b). In addition, TLR9 was not detected in H292 cells by RT-PCR (data not shown), indicating that DNA-sensing molecules other than TLR9 mediate this effect. Because poly(dA:dT) induces interferons in macrophages and fibroblasts [24-26], we next examined the expression levels of IFNA and IFNB after poly(dA:dT) stimulation in respiratory epithelial cells. The expression of IFNA1 did not increase significantly (Fig. 1c), whereas IFNBI expression was significantly increased by the stimulation (Fig. 1d). 


\section{STING was central for cytosolic DNA-induced MUC5AC mRNA expression}

An increasing body of evidence has demonstrated that STING is essential for immune cell responses to cytosolic DNA [27]. Therefore, to determine whether the same mechanism operates in bronchial epithelial cells, we knocked down STING expression using RNA interference (RNAi; Supplementary Fig. 1a). Knocking down STING suppressed poly(dA:dT)induced $M U C 5 A C$ expression to approximately one-third of the control value in H292 cells (Fig. 2a). We next investigated the involvement of other pathways known to respond to cytosolic nucleic acids. The RIG-I pathway is activated by single- or double-stranded RNA bearing a 5'triphosphate. Poly(dA:dT) is transcribed by RNAP III to produce a double-stranded RNA, which can therefore activate the pathway [28, 29]. To determine whether RIG-I is involved in MUC5AC expression, we used RNAi to silence RIG-I in H292 cells (Supplementary Fig. 1b). Poly(dA:dT)-induced MUC5AC expression was not suppressed but was instead enhanced (Fig. 2b). To ascertain whether this pathway might be relevant to MUC5AC expression, we inhibited RNAP III using the specific inhibitor ML-60218 [30] at a concentration that blocked the transcription of 5S rRNA (30 $\mu \mathrm{M})$ [28] (Supplementary Fig. 2). The inhibition of RNAP III had no statistically significant effect on poly(dA:dT)-induced $M U C 5 A C$ expression (Fig. 2c). cGAMP is produced by cGAS after cytosolic DNA recognition leads to STING activation [31]. Therefore, we next tested whether cGAMP could induce $M U C 5 A C$ expression. Treatment with cGAMP increased MUC5AC expression in a dose-dependent manner (Fig. 2d). The induction depended on STING, as silencing STING reduced cGAMP-induced MUC5AC expression (Fig. 2e), whereas the induction was increased by knocking down TRIM 32/56, a negative regulator of STING [32, 33] (Fig. 2e). 


\section{Nuclear factor kappa B (NF-אB) and specificity protein 1 (SP1) regulate MUC5AC mRNA} expression

NF- $\mathrm{BB}$ and IRF3 have been shown to be activated downstream of STING [34, 35]. We therefore investigated whether poly(dA:dT)-induced MUC5AC expression involved these

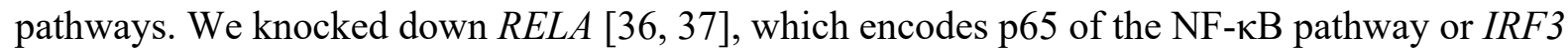
[38] (Supplementary Fig. 1e and 1f) and examined MUC5AC expression. The expression of MUC5AC mRNA was significantly suppressed by RELA RNAi, but not by IRF3 RNAi (Fig. 3a). Furthermore, we explored whether the transcription factor SP1, which has been shown to play an important role in MUC5AC expression [39, 40], is also involved in poly(dA:dT)-induced MUC5AC expression. Mithramycin A [21, 41], an inhibitor of SP1, suppressed poly(dA:dT)induced $M U C 5 A C$ expression in a dose-dependent manner (Fig. 3b).

\section{IFNB1 mRNA expression depended on RIG-I, but not STING and cGAMP}

$$
\text { STING was originally identified and annotated based on its central role in the }
$$
expression of IFNs in response to cytosolic DNA [42]. Therefore, we wanted to know whether STING helps regulate $I F N B 1$ expression. In contrast to $M U C 5 A C$, poly(dA:dT)-induced $I F N B 1$ mRNA expression was not repressed in STING-knockdown cells, but rather was significantly increased (Fig. 4a). cGAMP also failed to induce IFNB1 expression, irrespective of RNAi-based knockdown of TRIM 32/56 or STING (Fig. 4b). In contrast, however, IFNB1 expression was repressed by knocking down RIG-I (Fig. 4c). Therefore, we examined whether RNAP III was involved in the expression of IFNB1. Inhibition of RNAP III by ML-60218 failed to suppress IFNB1 expression (Fig. 4d). 


\section{DHX29 was involved in IFNB1 mRNA expression in response to cytosolic DNA} Because suppressing RNAP III function with the inhibitor did not affect IFNBI expression (Fig. 4d), we hypothesized that other molecules are involved in the RIG-I activation. One candidate is DHX29, an RNA helicase expressed in multiple tissues, which can sense intracellular nucleic acids and directly bind to and activate RIG- I [43]. DHX29 knockdown suppressed poly(dA:dT)-induced IFNB1 expression (Fig. 5a), whereas it did not suppress MUC5AC expression (Fig. 5b).

\section{IFNB mRNA expression in response to cytosolic DNA was suppressed by knocking down}

\section{NF-KB and IRF3}

We next investigated whether NF-אB and IRF3 are related to IFNB1 expression in response to cytosolic DNA signaling. IFNB1 expression was partially suppressed when the RELA or IRF3 genes were silenced with RNAi (Fig. 6a). In addition, mithramycin A did not affect cytosolic DNA-induced IFNB1 expression (Fig. 6b).

\section{Discussion}

Here, we report that cytosolic DNA induces mucin production in airway epithelial cells, which represent the front-line defense of airway tissues. In addition, we found that STING, whose importance in innate immunity is becoming increasingly recognized, played a critical role in cytosolic DNA-induced MUC5AC expression. Although STING is named for its role in inducing interferons in immune system cells, we found that STING was not required for IFN gene expression in bronchial epithelial cells. Intriguingly, our data indicate that IFNBI expression was instead dependent on RIG-I, which constitutes a different nucleic acid-sensing 
pathway. Our findings indicate that tissue specificity may occur among different cytosolic nucleic acid-sensing mechanisms. In other words, common cytosolic DNA stimuli responses use different nucleic acid-sensing systems to induce different target genes. There have been few reports on the selective use of such DNA-sensing mechanisms to date, and elucidation of the molecular mechanisms involved will be important in the future.

Foreign microorganisms are not merely sources of cytosolic DNA, as they also produce cGAMP themselves $[44,45]$. We showed that cGAMP loading strongly induced MUC5AC expression. These findings suggest an indispensable role for STING in $M U C 5 A C$ expression in the respiratory epithelium in response to infection. Cytosolic DNA can originate from both exogenous sources and self-DNA damage when DNA is released into the cytoplasm, resulting from mitochondrial disorders [46], UV irradiation, and DNA replication/recombination errors [47]. MUC5AC can be induced by a wide variety of factors other than respiratory pathogens, including chronic or acute inflammation, cigarette smoke, and air pollutants. Many of these factors are known to evoke mitochondrial disorders through cellular stresses, including endoplasmic reticulum stress and oxidative stress $[48,49]$. We therefore propose that mitochondrial DNA induces MUC5AC expression through STING activation; this hypothesis is currently being tested. Taken together, our results suggest that STING plays important roles in lung homeostasis and pathogenesis, at least in part by controlling mucin production in the airway epithelium.

Inhibiting SP1 reduced the expression of $M U C 5 A C$, which was induced by poly(dA:dT). A body of evidence shows that SP1 plays an important role in $M U C 5 A C$ expression [34]; however, our current results did not delineate whether SP1 was specifically involved in STINGmediated MUC5AC expression. In addition, no previous reports have described the activation of 
SP1 downstream of STING. As SP1 has been shown to be essential in MUC5AC induction by various stimuli, SP1 is likely an essential factor that supports $M U C 5 A C$ basal transcription, as shown for other SP1-regulated genes $[50,51]$.

STING was not involved in $I F N B$ expression in respiratory epithelial cells, consistent with a previous observation made by Sugimoto et al. [43]. Instead, they and we showed that DHX29 and RIG-I played roles in IFNB expression [38] (Figs. 4 and 5). Inhibiting RNAP III function did not affect IFNB1 expression, suggesting that a DHX29-RIG-I pathway rather than an RNAP III-RIG-I pathway regulates IFNBI expression in bronchial epithelial cells. Currently, the mechanisms underlying the cell-specificity of STING function are unknown and uncovering them will provide insights into the roles of STING in different tissue types.

When STING expression was knocked down, IFNB1 expression unexpectedly increased (Fig. 4a). Similarly, RIG-I knockdown increased MUC5AC expression (Fig. 2b). These findings suggest an interaction between STING and RIG-I in bronchial epithelial cells; this has been observed in other cell types [52]. Wu et al. [53] recently reported that the STING protein was degraded in an RIG-I-mediated manner and that knocking down RIG-I increased STING protein levels by reducing its degradation. Furthermore, RIG-I expression was increased by cytosolic DNA, which was mediated by STING; hence, STING knockdown inhibited the increase in $R I G-I$ expression [53]. The increase in $M U C 5 A C$ expression we observed after RIG-I knockdown (Fig. 2b) likely reflects this mechanism, in turn indicating that crosstalk may occur between DNA- and RNA-sensing mechanisms in bronchial epithelial cells.

This study had a few limitations. First, we only used a single type of epithelial cell line. Using normal human bronchial epithelial cells (NHBEs) would have provided results closely reflecting the physiological conditions of the airway but would have shown batch-to-batch 
variations in the results. In addition, it would have been more challenging to manipulate gene expression in NHBEs than in the NCI-H292 cell line. Nevertheless, our previous findings in NCI-H292 cells helped improve the understanding of airway epithelial cells [54-56]. Second, we focused on changes in MUC5AC gene expression, but did not MUC5AC protein expression. This is because understanding the mechanisms of $M U C 5 A C$ gene expression is vital for gaining insights into MUC5AC protein expression. The third limitation is that as a stimulant, we only used cytosolic poly(dA:dT). Using a natural immunostimulant such as a virus would more closely mimic inflammatory airway diseases but using such complex organisms would activate multiple pathways simultaneously. Using poly(dA:dT) enabled us to focus on how MUC5AC was expressed by cytosolic DNA.

In summary, our findings suggest that cytosolic DNA induces $M U C 5 A C$ and $I F N B 1$ gene expression through different pathways, including STING- and RIG-I- pathways, in human bronchial epithelial cells. Our data also suggest functional interactions between these two pathways. Therefore, controlling STING function in the airway epithelium may be useful in chronic lung disease therapy.

\section{List of abbreviations:}

DAMP, damage-associated molecular-pattern; FBS, fetal bovine serum; TGF, transforming growth factor; PRRs, pattern-recognition receptors; RNAP, RNA polymerase; RIG-I, retinoic acid-inducible gene-I; STING, stimulator of interferon genes; cGAMP, cyclic GMP-AMP; cGAS, cGAMP synthase; RT, reverse transcription; NF-Kb, nuclear factor kappa B; NHBEs, normal human bronchial epithelial cells.

\section{Declarations}


275 Not applicable.

\section{Consent for publication}

277 Not applicable.

\section{Availability of data and materials}

279 The datasets supporting the conclusions of this article are included within the article and its 280 additional supplemental files.

\section{Competing interests}

282 The authors have no conflict of interest and no financial support to disclose.

283 Funding

284 There was no funding for this study.

\section{Authors' contributions}

286 MO, TT, YN, AA, TO, AS, SY, and HA conceived and designed the experiments; MO, TT, YN, 287 HY, AA, TO, SY, and TI performed the experiments; MO, TT, AA, and HA analyzed the data; 288 MO, TT, SY, TI, YK, and HA drafted the manuscript.

\section{Acknowledgements}

290 We thank Sachiko Hayashi and Kiyoe Ishii for providing technical assistance. We also thank all members of the Department of Pediatrics of Gunma University Graduate School of Medicine for their help and advice. We would like to thank Editage (www.editage.jp) for English language editing.

\section{References}

1. Weitnauer M, Mijosek V, Dalpke AH. Control of local immunity by airway epithelial cells. Mucosal Immunol 2016; 9: 287-98.

2. Roy MG, Livraghi-Butrico A, Fletcher AA, McElwee MM, Evans SE, Boerner RM, Alexander SN, et al. Muc5b is required for airway defence. Nature 2014; 505: 412. 
3. Ehre C, Worthington EN, Liesman RM, Grubb BR, Barbier D, O'Neal WK, et al. Overexpressing mouse model demonstrates the protective role of Muc5ac in the lungs. Proc Natl Acad Sci U S A 2012; 109: 16528-33.

4. Kuyper LM, Pare PD, Hogg JC, Lambert RK, Ionescu D, Woods R, et al. Characterization of airway plugging in fatal asthma. Am J Med 2003; 115: 6-11.

5. Takeyama K, Dabbagh K, Lee HM, Agusti C, Lausier JA, Ueki IF, et al. Epidermal growth factor system regulates mucin production in airways. Proc Natl Acad Sci U S A 1999; 96: 3081-6.

6. Shao MX, Nakanaga T, Nadel JA. Cigarette smoke induces MUC5AC mucin overproduction via tumor necrosis factor- $\alpha$-converting enzyme in human airway epithelial (NCI-H292) cells. Am J Physiol Lung Cel Mol Physiol 2004; 287: L420-7.

7. Rubartelli A, Lotze MT. Inside, outside, upside down: damage-associated molecular-pattern molecules (DAMPs) and redox. Trends Immunol 2007; 28: 429-36.

8. Tang D, Kang R, Coyne CB, Zeh HJ, Lotze MT. PAMPs and DAMPs: signal 0s that spur autophagy and immunity. Immunol Rev 2012; 249: 158-75.

9. Zhang Z, Yuan B, Bao M, Lu N, Kim T, Liu YJ. The helicase DDX41 senses intracellular DNA mediated by the adaptor STING in dendritic cells. Nat Immunol 2011; 12: 959-65.

10. Corrales L, Woo SR, Williams JB, McWhirter SM, Dubensky TW, Jr., Gajewski TF. Antagonism of the STING pathway via activation of the AIM2 inflammasome by intracellular DNA. J Immunol 2016; 196: 3191-8.

11. Choi MK, Wang Z, Ban T, Yanai H, Lu Y, Koshiba R, et al. A selective contribution of the RIG-I-like receptor pathway to type I interferon responses activated by cytosolic DNA. Proc Natl Acad Sci U S A 2009; 106: 17870-5. 
12. Wu X, Wu FH, Wang X, Wang L, Siedow JN, Zhang W, Pei ZM. Molecular evolutionary and structural analysis of the cytosolic DNA sensor cGAS and STING. Nucleic Acids Res 2014; 42: 8243-57.

13. O'neill LA. Immunology. Sensing the dark side of DNA. Science 2013; 339: 763-4.

14. Burdette DL, Monroe KM, Sotelo-Troha K, Iwig JS, Eckert B, Hyodo M, et al. STING is a direct innate immune sensor of cyclic di-GMP. Nature 2011; 478: 515.

15. Sun L, Wu J, Du F, Chen X, Chen ZJ. Cyclic GMP-AMP synthase is a cytosolic DNA sensor that activates the type I interferon pathway. Science 2013; 339: 786-91.

16. Dunphy G, Flannery SM, Almine JF, Connolly DJ, Paulus C, Jonsson KL, et al. Noncanonical activation of the DNA sensing adaptor STING by ATM and IFI16 mediates NF-kappaB signaling after nuclear DNA damage. Mol Cell 2018; 71: 745-60.e745.

17. Kitai Y, Kawasaki T, Sueyoshi T, Kobiyama K, Ishii KJ, Zou J, et al. DNA-containing exosomes derived from cancer cells treated with topotecan activate a STING-dependent pathway and reinforce antitumor immunity. J Immunol 2017; 198: 1649-59.

18. Stetson DB, Medzhitov R. Recognition of cytosolic DNA activates an IRF3-dependent innate immune response. Immunity 2006; 24: 93-103.

19. Tadaki H, Arakawa H, Mizuno T, Suzuki T, Takeyama K, Mochizuki H, et al. Doublestranded RNA and TGF-alpha promote MUC5AC induction in respiratory cells. $J$ Immunol 2009; 182: 293-300.

20. Takami S, Mizuno T, Oyanagi T, Tadaki H, Suzuki T, Muramatsu K, et al. Glucocorticoids inhibit MUC5AC production induced by transforming growth factor-alpha in human respiratory cells. Allergol Int 2012; 61: 451-9. 
21. Oyanagi T, Takizawa T, Aizawa A, Solongo O, Yagi H, Nishida Y, et al. Suppression of MUC5AC expression in human bronchial epithelial cells by interferon-gamma. Allergol Int 2017; 66: 75-82.

22. Latz E, Schoenemeyer A, Visintin A, Fitzgerald KA, Monks BG, Knetter CF, et al. TLR9 signals after translocating from the ER to CpG DNA in the lysosome. Nat Immunol 2004; 5: $190-8$.

23. Hemmi H, Takeuchi O, Kawai T, Kaisho T, Sato S, Sanjo H, et al. A Toll-like receptor recognizes bacterial DNA. Nature 2000; 408: 740.

24. Chamilos G, Gregorio J, Meller S, Lande R, Kontoyiannis DP, Modlin RL, et al. Cytosolic sensing of extracellular self-DNA transported into monocytes by the antimicrobial peptide LL37. Blood 2012; 120: 3699-707.

25. Lippmann J, Rothenburg S, Deigendesch N, Eitel J, Meixenberger K, van Laak V, et al. IFNbeta responses induced by intracellular bacteria or cytosolic DNA in different human cells do not require ZBP1 (DLM-1/DAI). Cell Microbiol 2008; 10: 2579-88.

26. Melchjorsen J, Rintahaka J, Soby S, Horan KA, Poltajainen A, Ostergaard Let al. Early innate recognition of herpes simplex virus in human primary macrophages is mediated via the MDA5/MAVS-dependent and MDA5/MAVS/RNA polymerase III-independent pathways. J Virol 2010; 84: 11350-8.

27. Burdette DL, Vance RE. STING and the innate immune response to nucleic acids in the cytosol. Nat Immunol 2013; 14: 19-26.

28. Chiu YH, Macmillan JB, Chen ZJ. RNA polymerase III detects cytosolic DNA and induces type I interferons through the RIG-I pathway. Cell 2009; 138: 576-91. 
29. Ablasser A, Bauernfeind F, Hartmann G, Latz E, Fitzgerald KA, Hornung V. RIG-Idependent sensing of poly(dA:dT) through the induction of an RNA polymerase IIItranscribed RNA intermediate. Nat Immunol 2009; 10: 1065-72.

30. Wu L, Pan J, Thoroddsen V, Wysong DR, Blackman RK, Bulawa CE, et al. Novel smallmolecule inhibitors of RNA polymerase III. Eukaryotic Cell 2003; 2: 256-64.

31. Tao J, Zhou X, Jiang Z. cGAS-cGAMP-STING: the three musketeers of cytosolic DNA sensing and signaling. IUBMB Life 2016; 68: 858-70.

32. Zhang J, Hu MM, Wang YY, Shu HB. TRIM32 protein modulates type I interferon induction and cellular antiviral response by targeting MITA/STING protein for K63-linked ubiquitination. J Biol Chem 2012; 287: 28646-55.

33. Tsuchida T, Zou J, Saitoh T, Kumar H, Abe T, Matsuura Y, Kawai T, Akira S. The ubiquitin ligase TRIM56 regulates innate immune responses to intracellular double-stranded DNA. Immunity 2010; 33: 765-76.

34. Abe T, Barber GN. Cytosolic-DNA-mediated, STING-dependent proinflammatory gene induction necessitates canonical NF-kappaB activation through TBK1. J Virol 2014; 88: $5328-41$.

35. Liu S, Cai X, Wu J, Cong Q, Chen X, Li T, et al. Phosphorylation of innate immune adaptor proteins MAVS, STING, and TRIF induces IRF3 activation. Science 2015; 347: aaa2630.

36. Ghosh S, May MJ, Kopp EB. NF-kappa B and Rel proteins: evolutionarily conserved mediators of immune responses. Annu Rev Immunol 1998; 16: 225-60.

37. Ghosh S, Karin M. Missing pieces in the NF-кB puzzle. Cell 2002; 109: S81-96.

38. Ysebrant de Lendonck L, Martinet V, Goriely S. Interferon regulatory factor 3 in adaptive immune responses. Cell Mol Life Sci 2014; 71: 3873-83. 
39. Jonckheere N, Van Der Sluis M, Velghe A, Buisine MP, Sutmuller M, et al. Transcriptional activation of the murine Muc5ac mucin gene in epithelial cancer cells by TGFbeta/Smad4 signalling pathway is potentiated by Sp1. Biochem J 2004; 377: 797-808.

40. Di YP, Zhao J, Harper R. Cigarette smoke induces MUC5AC protein expression through the activation of Sp1. J Biol Chem 2012; 287: 27948-58.

41. Jia Z, Zhang J, Wei D, Wang L, Yuan P, Le X, et al. Molecular basis of the synergistic antiangiogenic activity of bevacizumab and mithramycin A. Cancer Res 2007; 67: 487885.

42. Chen Q, Sun L, Chen ZJ. Regulation and function of the cGAS-STING pathway of cytosolic DNA sensing. Nat Immunol 2016; 17: 1142-9.

43. Sugimoto N, Mitoma H, Kim T, Hanabuchi S, Liu YJ. Helicase proteins DHX29 and RIG-I cosense cytosolic nucleic acids in the human airway system. Proc Natl Acad Sci US A 2014; 111: 7747-52.

44. Liu Y, Goulet ML, Sze A, Hadj SB, Belgnaoui SM, Lababidi RR, et al. RIG-I-mediated STING upregulation restricts Herpes simplex virus 1 infection. J Virol 2016; 90: 940619.

45. Ablasser A, Schmid-Burgk JL, Hemmerling I, Horvath GL, Schmidt T, Latz E, et al. Cell intrinsic immunity spreads to bystander cells via the intercellular transfer of cGAMP. Nature 2013; 503: 530.

46. Liu S, Feng M, Guan W. Mitochondrial DNA sensing by STING signaling participates in inflammation, cancer and beyond. Int J Cancer 2016; 139: 736-41. 
47. Hartlova A, Erttmann SF, Raffi FA, Schmalz AM, Resch U, Anugula S, et al. DNA damage primes the type I interferon system via the cytosolic DNA sensor STING to promote antimicrobial innate immunity. Immunity 2015; 42: 332-43.

48. Rongvaux A, Jackson R, Harman CC, Li T, West AP, de Zoete MR, et al. Apoptotic caspases prevent the induction of type I interferons by mitochondrial DNA. Cell 2014; 159: 1563 77.

49. White MJ, McArthur K, Metcalf D, Lane RM, Cambier JC, Herold MJ, et al. Apoptotic caspases suppress mtDNA-induced STING-mediated type I IFN production. Cell 2014; 159: $1549-62$.

50. Liu J, Yang H, Liu W, Cao X, Feng X. Sp1 and Sp3 regulate the basal transcription of receptor activator of nuclear factor kappa B ligand gene in osteoblasts and bone marrow stromal cells. $J$ Cell Biochem 2005; 96: 716-27.

51. Xu HG, Jin R, Ren W, Zou L, Wang Y, Zhou GP. Transcription factors Sp1 and Sp3 regulate basal transcription of the human IRF-3 gene. Biochimie 2012; 94: 1390-7.

52. Zevini A, Olagnier D, Hiscott J. Crosstalk between cytoplasmic RIG-I and STING sensing pathways. Trends Immunol 2017; 38: 194-205.

53. Wu X, Yang J, Na T, Zhang K, Davidoff AM, Yuan BZ, et al. RIG-I and IL-6 are negativefeedback regulators of STING induced by double-stranded DNA. PLoS One 2017; 12: e0182961.

54. Kim S, Beyer BA, Lewis C, Nadel JA. Normal CFTR inhibits epidermal growth factor receptor-dependent pro-inflammatory chemokine production in human airway epithelial cells. PLoS One 2013; 8: e72981. 
433 55. Kim S, Lewis C, Nadel JA. Epidermal growth factor receptor reactivation induced by E-

434

435

436

437

438

439 prostanoid-3 receptor-and tumor necrosis factor-alpha-converting enzyme-dependent feedback exaggerates interleukin-8 production in airway cancer (NCI-H292) cells. Exp Cell Res 2011; 317: 2650-60.

56. Kim S, Lewis C, Nadel JA. CCL20/CCR6 feedback exaggerates epidermal growth factor receptor-dependent MUC5AC mucin production in human airway epithelial (NCI-H292) cells. J Immunol 2011; 186: 3392-400. 


\section{Figure legends}

Fig. 1. Cytosolic DNA induced $M U C 5 A C$ and $I F N B 1$ mRNA expression. (a and b) RT-PCR for MUC5AC mRNA. (a) NCI-H292 cells were treated with a plasmid (with or without polyethylenimine) or stimulated with TGF- $\alpha(4 \mathrm{ng} / \mathrm{mL})$ and poly(I:C) for $6 \mathrm{~h}(\mathrm{n}=8)$. (b) Plasmid and poly(dA:dT) $(0.5 \mu \mathrm{g} /$ well $)$ lipofected into H292 cells $(\mathrm{n}=8, P<0.001)$. (c) IFNA1 mRNA expression (with or without poly[dA:dT] stimulation) was determined in $\mathrm{H} 292$ cells $(\mathrm{n}=4, P=$ 0.6678). (d) Expression of IFNB1 mRNA, with or without poly(dA:dT) (n=4,P<0.001). The data are presented as fold changes relative to untreated controls after being normalized to $18 \mathrm{~S}$ rRNA levels. The bars in panels a-d represent means \pm SEMs. ${ }^{* * *} P<0.001$, as determined using Tukey’ test.

\section{Fig. 2. MUC5AC mRNA expression induced by cytosolic DNA required STING and}

cGAMP. (a and b) H292 cells were transfected with siRNAs against STING (a) or RIG-I (b) mRNA, or a control siRNA, for $6 \mathrm{~h}$ and then treated with poly(dA:dT) for an additional $6 \mathrm{~h}$. MUC5AC-expression levels were determined by RT-PCR and are presented as fold changes relative to that without poly $(\mathrm{dA}: \mathrm{dT})(\mathrm{A}, \mathrm{n}=14, * * * P<0.001 ; \mathrm{B}, \mathrm{n}=8, * * * P<0.001)$. (c) $\mathrm{H} 292$ cells were treated with $30 \mu \mathrm{M}$ ML-60218 for $2 \mathrm{~h}$ and then with poly(dA:dT) for $6 \mathrm{~h}$. MUC5ACexpression levels were determined by RT-PCR and are expressed as fold changes relative to that in untreated cells $(\mathrm{n}=4, P=0.111)$. (d and e) Effects of cGAMP on MUC5AC expression. H292 cells were incubated with cGAMP $(3.3$ or $10 \mu \mathrm{g} / \mathrm{mL})$ for $16 \mathrm{~h}(\mathrm{n}=4, * * * P<0.001)$. (e) H292 cells were treated with control siRNA, siSTING, or siTRIM32/56 for $6 \mathrm{~h}$ before cGAMP stimulation. ( $\mathrm{n}=4,{ }^{*} P=0.012$ and $\left.{ }^{* * *} P<0.001\right)$. The error bars in panels A-E represent means \pm SEMs. ${ }^{* * *} P<0.001,{ }^{*} P<0.05$, as determined using the Tukey test for the experiments shown in panel B and the Dunnett test for the experiments shown in the other panels. 
Fig. 3. NF-кB and SP1 were involved in cytosolic DNA-induced $M U C 5 A C$ expression. (a)

H292 cells were transfected with RELA, IRF3, or control siRNA for $6 \mathrm{~h}$ and then stimulated with poly(dA:dT) for $6 \mathrm{~h}(\mathrm{n}=8)$. Knocking down the RELA gene suppressed $M U C 5 A C$ expression $(P$ $<0.001)$. (b) Cells were treated with poly(dA:dT) for $4.5 \mathrm{~h}$ and stimulated with different concentrations of the SP1 inhibitor mithramycin for $17 \mathrm{~h}$. MUC5AC expression was suppressed by mithramycin in a dose-dependent manner $(\mathrm{n}=4, * * P=0.004$ and $* * * P<0.001)$. The error bars in (a) and (b) represent means \pm SEMs. ${ }^{* * *} P<0.001,{ }^{* *} P<0.01$ using the Dunnett test.

Fig. 4. RIG-I but not cGAMP or STING played a role in IFNB1 upregulation. (a) IFNBI expression was determined after cells were treated with a control or STING siRNA for $6 \mathrm{~h}$ and stimulated with poly(dA:dT) for an additional $6 \mathrm{~h}$. IFNB1 expression increased after STING knockdown ( $\mathrm{n}=8, P<0.001)$. (b) Cells were treated with the indicated siRNAs for $6 \mathrm{~h}$ and then with cGAMP for $16 \mathrm{~h}$. IFNB1 mRNA expression did not increased after incubation with either 3.3 or $10 \mu \mathrm{g} / \mathrm{mL}$ cGAMP, using any of the three siRNAs $(\mathrm{n}=4)$. (c) Cells were transfected with siRNA against $R I G-I$ and stimulated with poly(dA:dT). IFNB1 expression decreased after RIG-I knockdown (n $=4, P<0.001)$. (d) Cells were treated with the RNA polymerase III inhibitor ML60218 for $2 \mathrm{~h}$ and then stimulated with poly(dA:dT) for $6 \mathrm{~h}$. No change in IFNB1 expression was observed ( $\mathrm{n}=4, P=0.873)$. The bars in panels a-d represent means \pm SEMs. $* * * P<0.001$, as

483 determined using the Tukey test for the experiments shown in panel $\mathrm{b}$ and the Dunnett test for 484 the experiments shown in the other panels. 
Fig. 5. DHX29 participated in cytosolic DNA-induced IFNB1 expression. (a and b) Cells

487

488

489

490

491

492

493

494

495

496

497

498

499 were treated with siRNA for $6 \mathrm{~h}$ and stimulated with poly(dA:dT) for $6 \mathrm{~h}$. The mRNA expression levels of (a) IFNB1 and (b) MUC5AC were determined by RT-PCR. IFNB1 was inhibited by DHX29 knockdown $(\mathrm{n}=12, P=0.003)(\mathrm{a})$, whereas a significant difference was not observed for MUC5AC expression (b) $(\mathrm{n}=12, P=0.270)$. The error bars represent means \pm SEMs. $* * P<$ 0.01 , as determined using the Tukey test.

Fig. 6. NF-אB and IRF3, but not SP1, were involved in IFNB1 mRNA expression. (a) Cells were treated with siRNA for $6 \mathrm{~h}$ and then stimulated with poly(dA:dT) for $6 \mathrm{~h}$. IFNB1 expression was suppressed by RELA knockdown $(P=0.003)$ and $I R F 3$ knockdown $(P=0.002)(\mathrm{n}=12)$. (b) Cells were treated with poly(dA:dT) for $4.5 \mathrm{~h}$ and stimulated with the SP1 inhibitor mithramycin A for $17 \mathrm{~h}(\mathrm{n}=4)$. The error bars represent means \pm SEMs. $* * P<0.01$, as determined using the Dunnett test. 
a

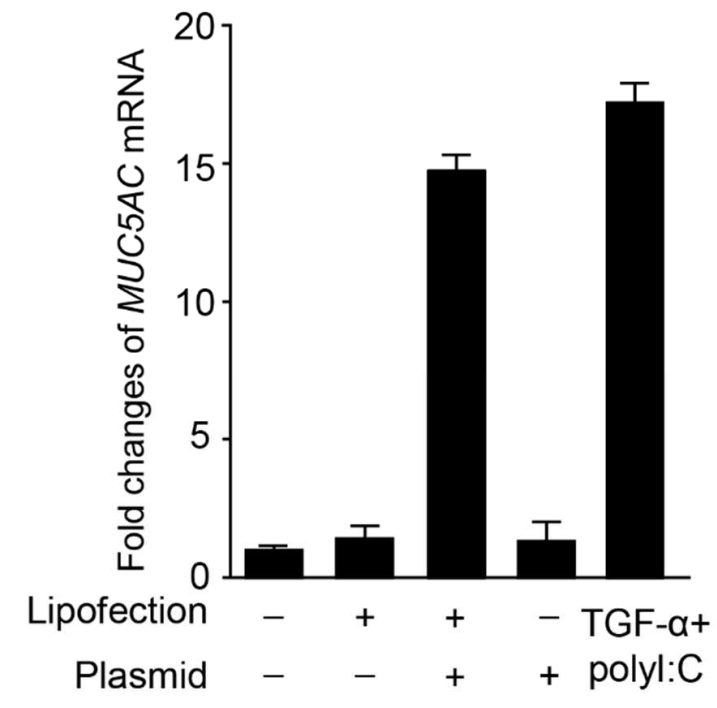

b

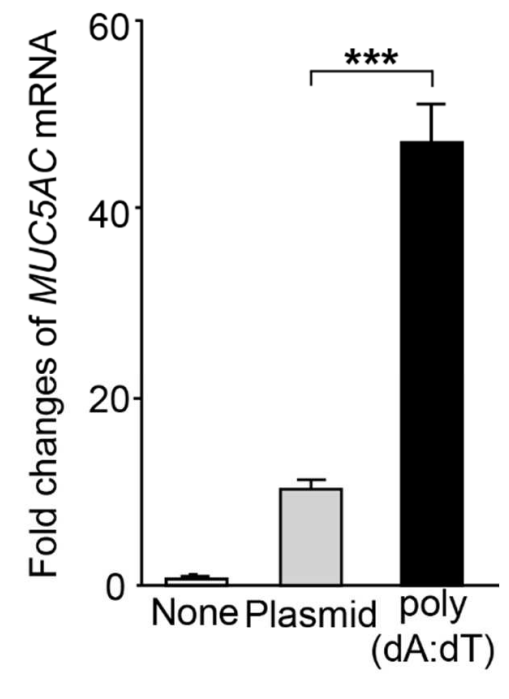

C

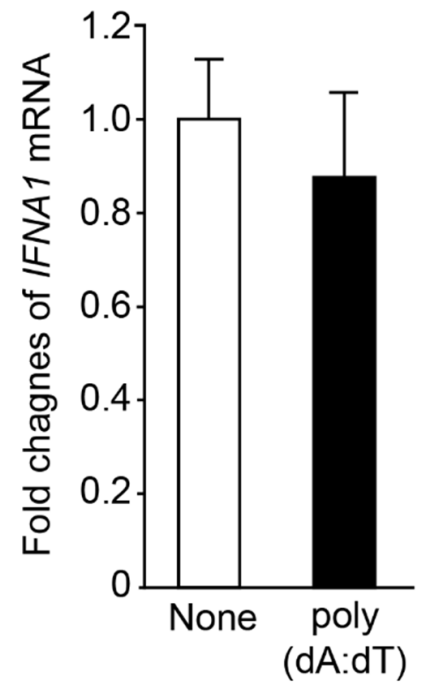

d

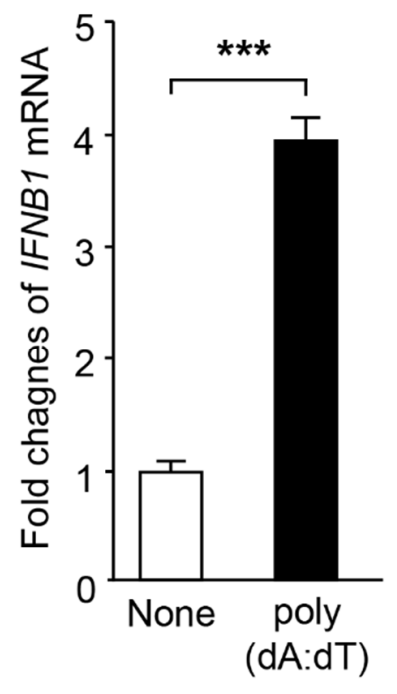

Figure 1. Ota et al. 
a

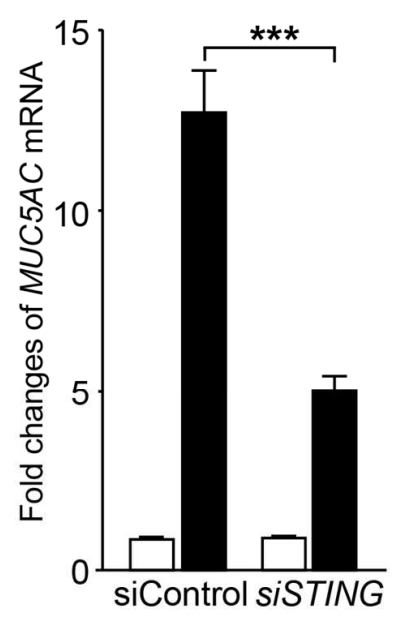

d

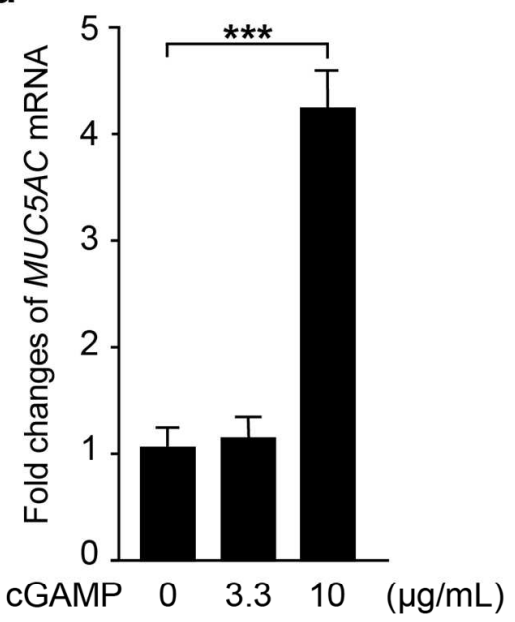

b

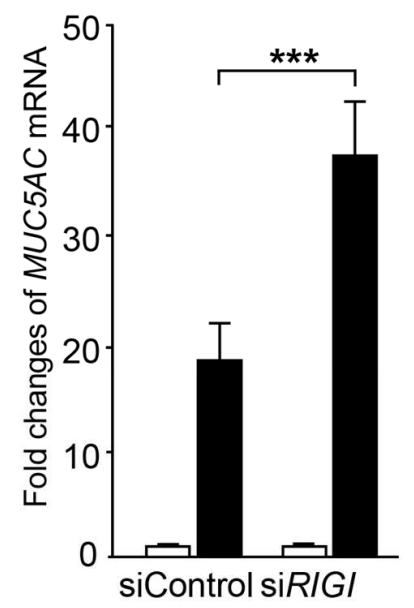

e

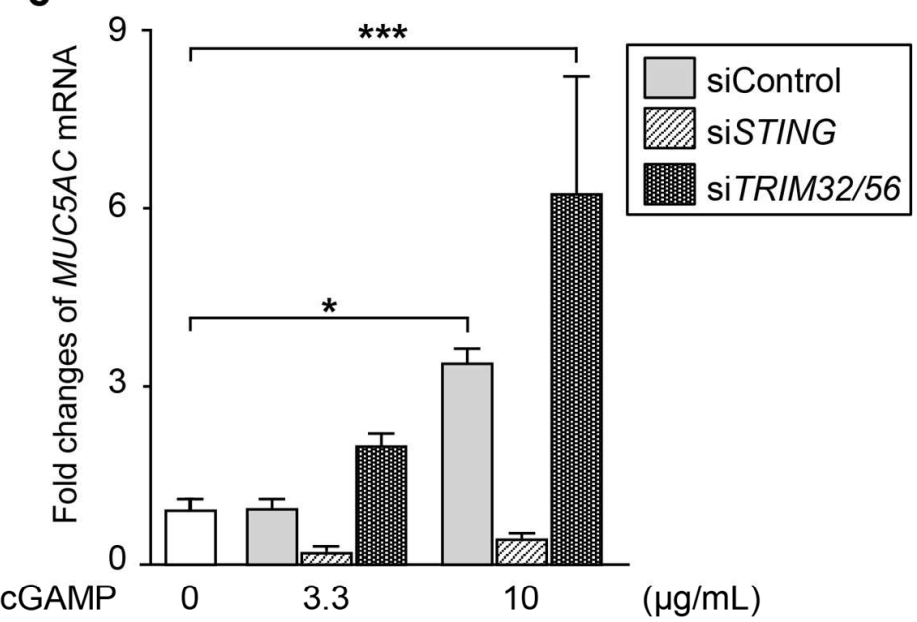

Figure 2. Ota et al. 
a

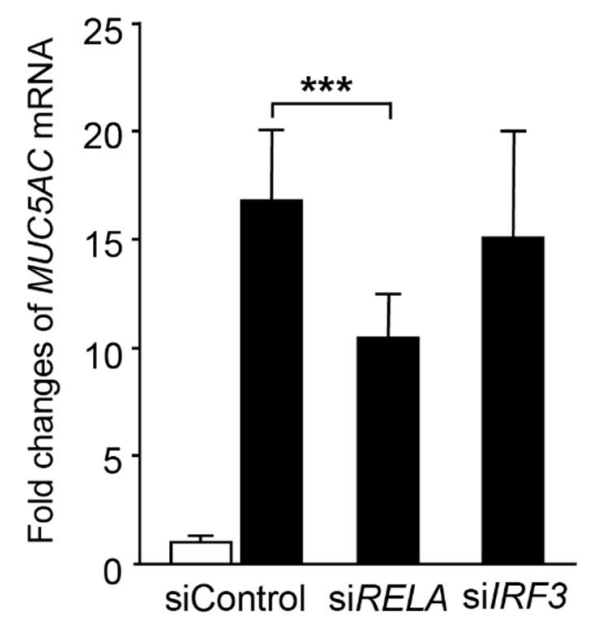

b

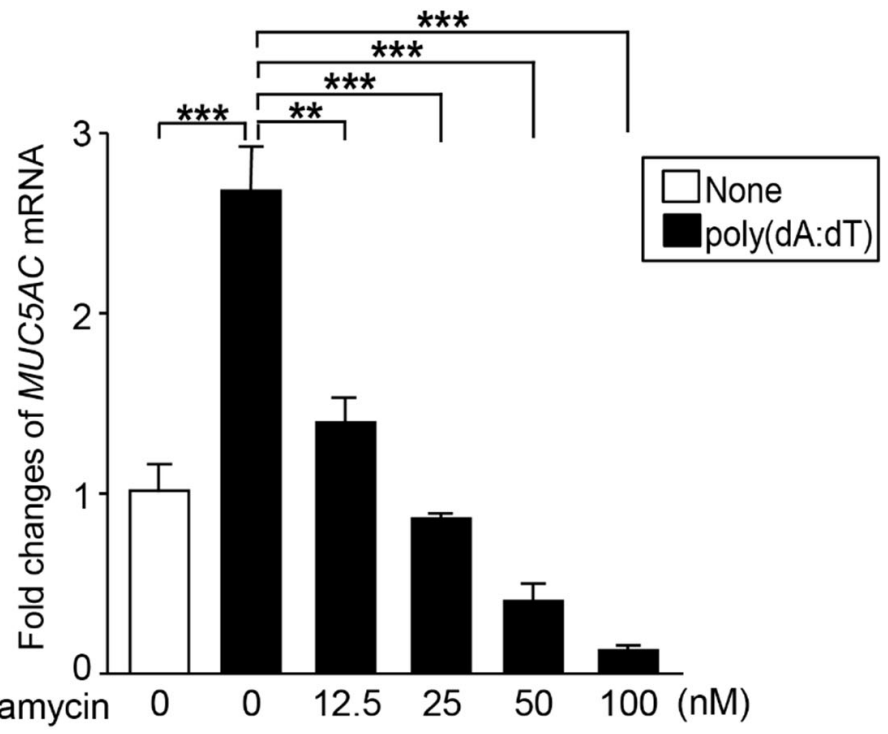

Figure 3. Ota et al. 
a

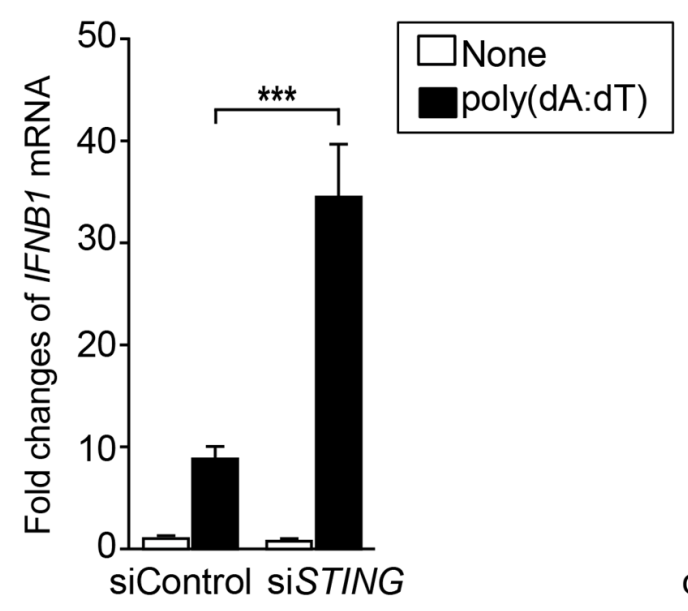

C

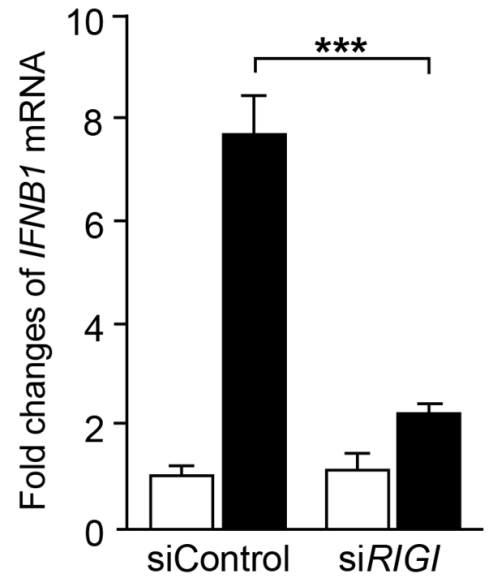

b

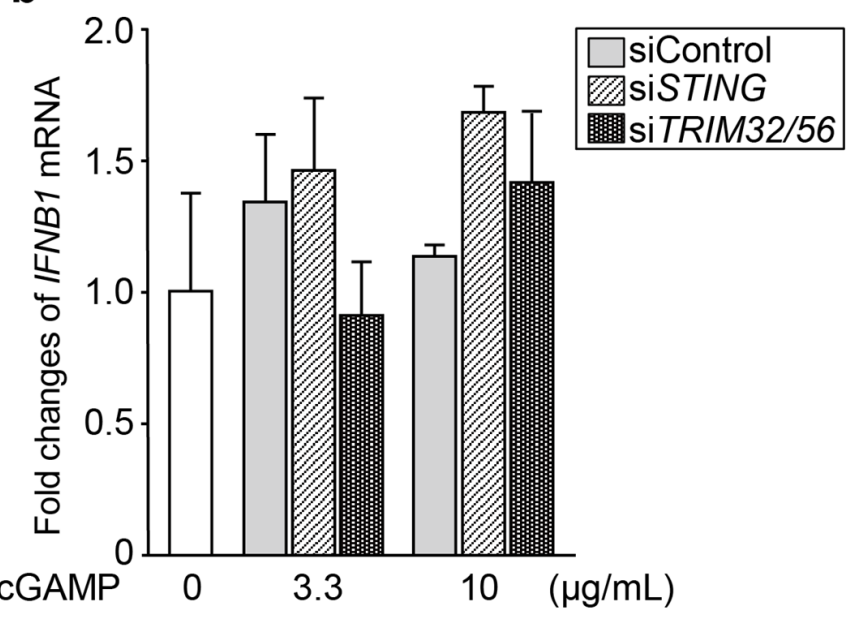

d

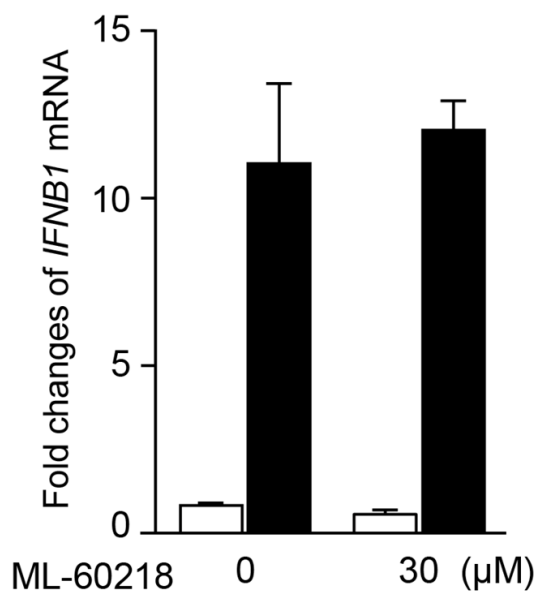

Figure 4. Ota et al. 
a

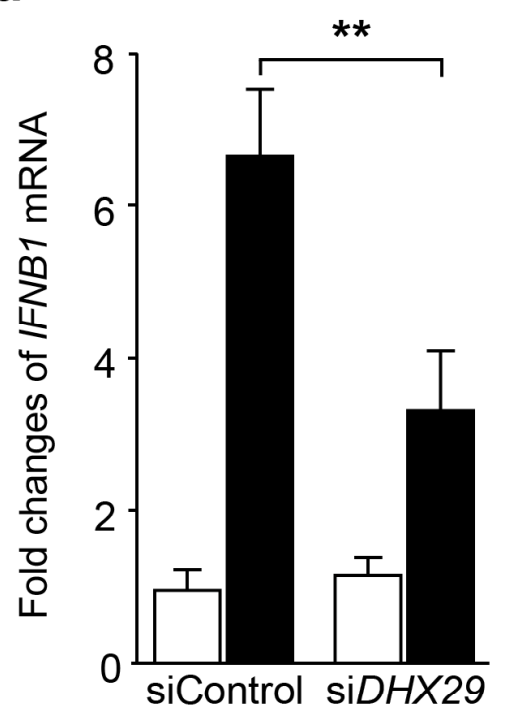

b

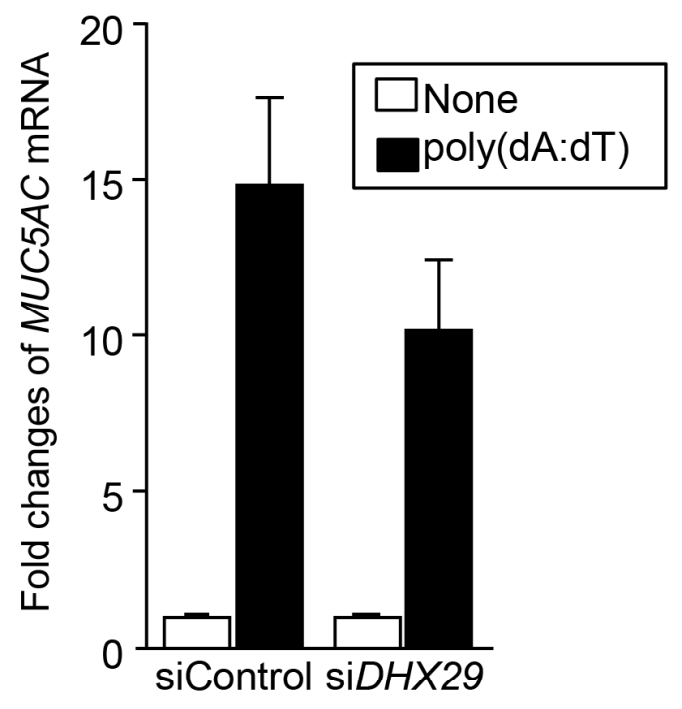

Figure 5. Ota et al. 
a

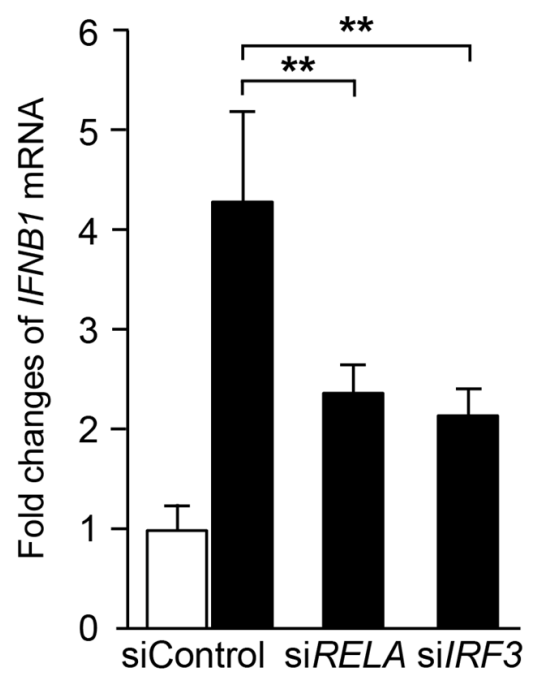

b

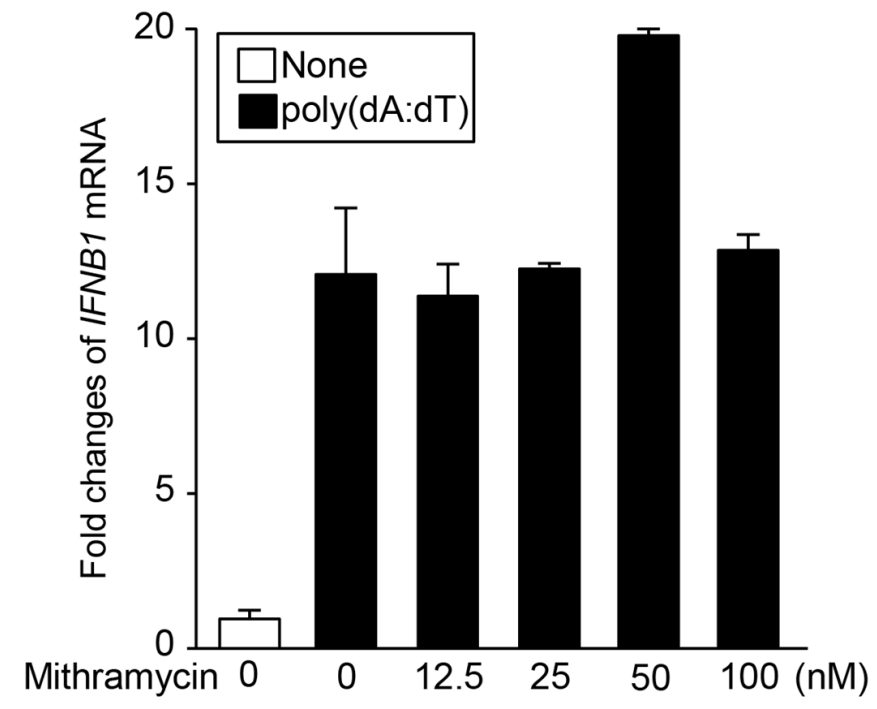

Figure 6. Ota et al. 


\section{Figures}
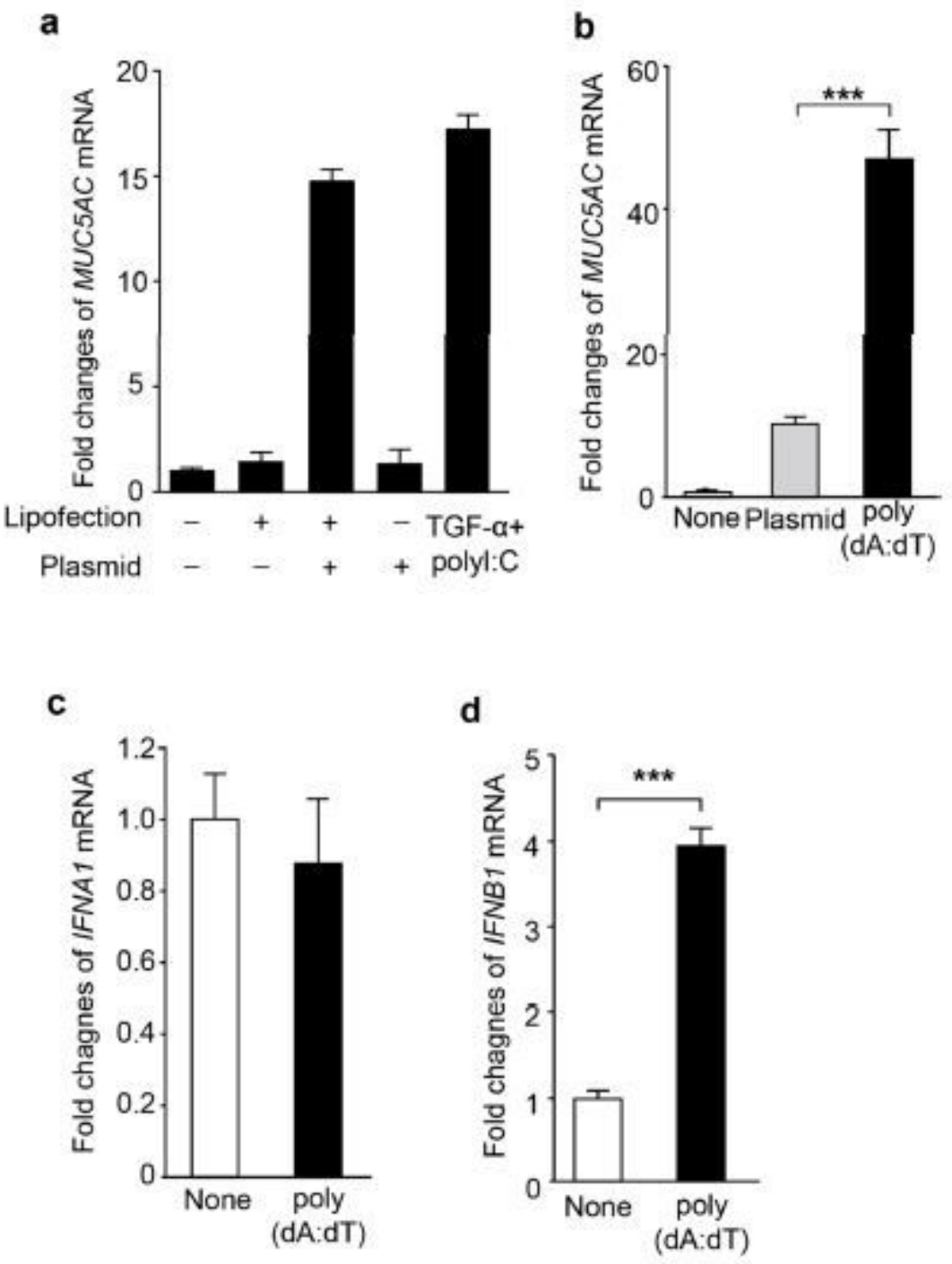

\section{Figure 1}

Cytosolic DNA induced MUC5AC and IFNB1 mRNA expression. (a and b) RT-PCR for MUC5AC mRNA. (a) $\mathrm{NCl}-\mathrm{H} 292$ cells were treated with a plasmid (with or without polyethylenimine) or stimulated with TGF-a (4 $\mathrm{ng} / \mathrm{mL})$ and poly $(\mathrm{l}: \mathrm{C})$ for $6 \mathrm{~h}(\mathrm{n}=8)$. (b) Plasmid and poly $(\mathrm{dA}: \mathrm{dT})(0.5 \mu \mathrm{g} /$ well) lipofected into H292 cells ( $n=8, P<0.001)$. (c) IFNA1 mRNA expression (with or without poly[dA:dT] stimulation) was determined in H292 cells ( $n=4, P=0.6678)$. (d) Expression of IFNB1 mRNA, with or without poly $(d A: d T)(n=4, P<$ $0.001)$. The data are presented as fold changes relative to untreated controls after being normalized to $18 \mathrm{~S}$ rRNA levels. The bars in panels $\mathrm{a}-\mathrm{d}$ represent means \pm SEMs. ${ }^{\star \star *} \mathrm{P}<0.001$, as determined using Tukey' test. 

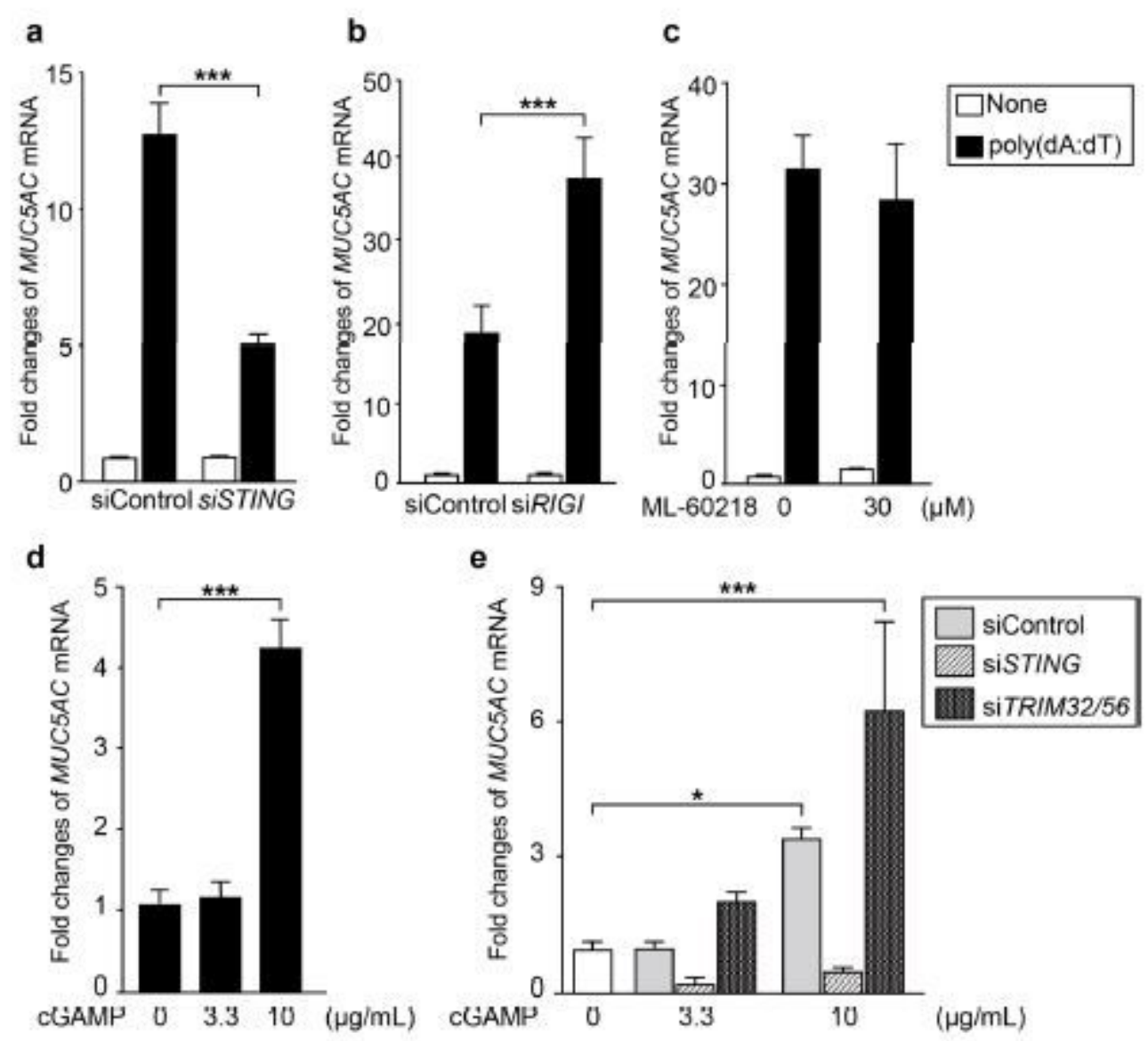

\section{Figure 2}

MUC5AC mRNA expression induced by cytosolic DNA required STING and cGAMP. (a and b) H292 cells were transfected with siRNAs against STING (a) or RIG-I (b) mRNA, or a control siRNA, for $6 \mathrm{~h}$ and then treated with poly (dA:dT) for an additional $6 \mathrm{~h}$. MUC5AC-expression levels were determined by RT-PCR and

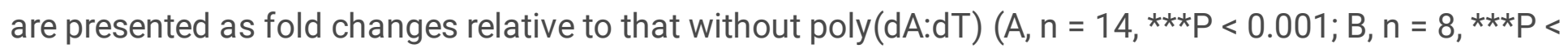
0.001). (c) H292 cells were treated with $30 \mu \mathrm{M} M L-60218$ for $2 \mathrm{~h}$ and then with poly(dA:dT) for $6 \mathrm{~h}$. MUC5AC expression levels were determined by RT-PCR and are expressed as fold changes relative to that in untreated cells $(n=4, P=0.111)$. ( $d$ and e) Effects of cGAMP on MUC5AC expression. H292 cells were incubated with cGAMP (3.3 or $10 \mu \mathrm{g} / \mathrm{mL}$ ) for $16 \mathrm{~h}(\mathrm{n}=4$, $* \star \star \mathrm{P}<0.001)$. (e) H292 cells were treated with control siRNA, siSTING, or siTRIM32/56 for $6 \mathrm{~h}$ before cGAMP stimulation. $(n=4, * P=0.012$ and $* \star * P<$ $0.001)$. The error bars in panels $A-E$ represent means \pm SEMs. ${ }^{\star *} * P<0.001, * P<0.05$, as determined using the Tukey test for the experiments shown in panel $B$ and the Dunnett test for the experiments shown in the other panels. 

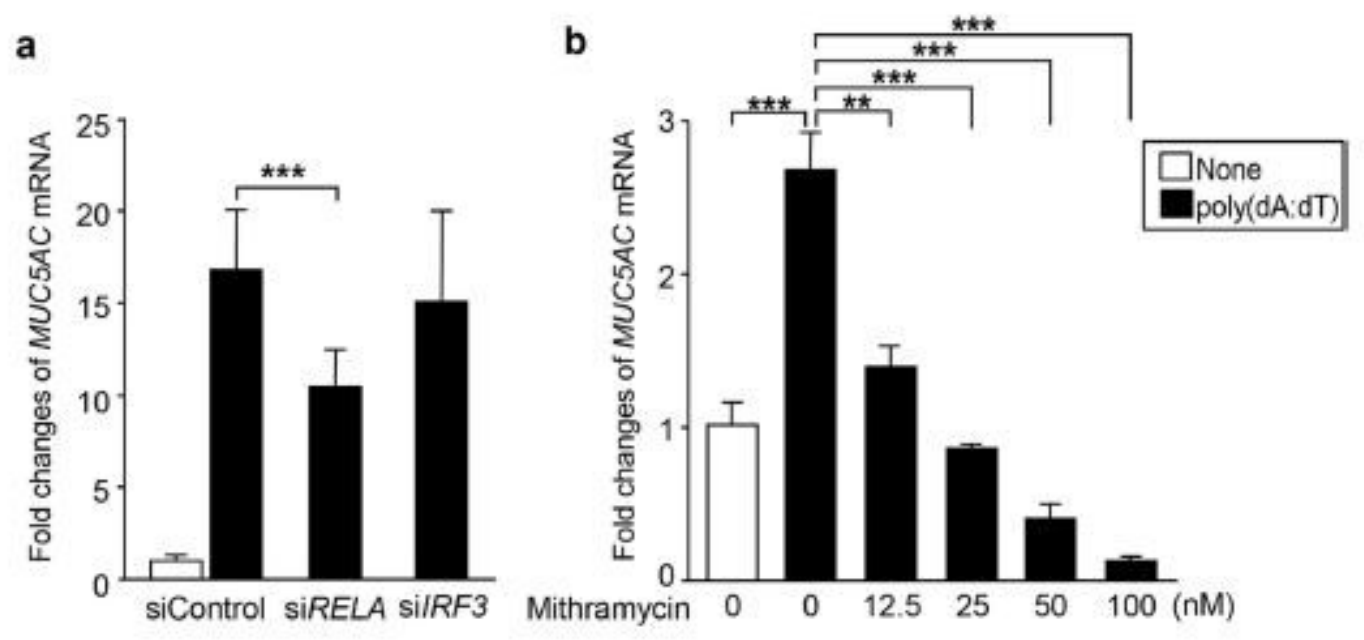

Figure 3

NF-KB and SP1 were involved in cytosolic DNA-induced MUC5AC expression. (a) H292 cells were transfected with RELA, IRF3, or control siRNA for $6 \mathrm{~h}$ and then stimulated with poly (dA:dT) for $6 \mathrm{~h}(\mathrm{n}=8)$. Knocking down the RELA gene suppressed MUC5AC expression $(P<0.001)$. (b) Cells were treated with poly (dA:dT) for $4.5 \mathrm{~h}$ and stimulated with different concentrations of the SP1 inhibitor mithramycin for 17 h. MUC5AC expression was suppressed by mithramycin in a dose-dependent manner $(n=4, * * P=0.004$ and $\left.{ }^{\star * \star} P<0.001\right)$. The error bars in (a) and (b) represent means \pm SEMs. ${ }^{\star \star *} P<0.001,{ }^{*} \mathrm{P}<0.01$ using the Dunnett test. 
a

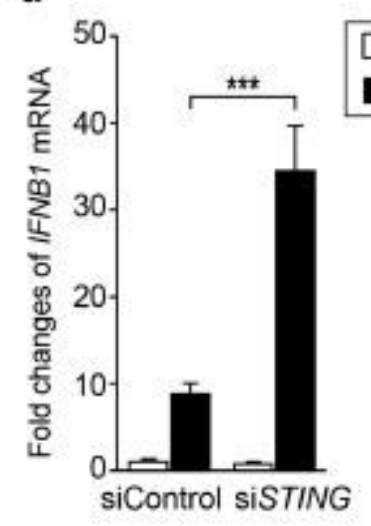

C

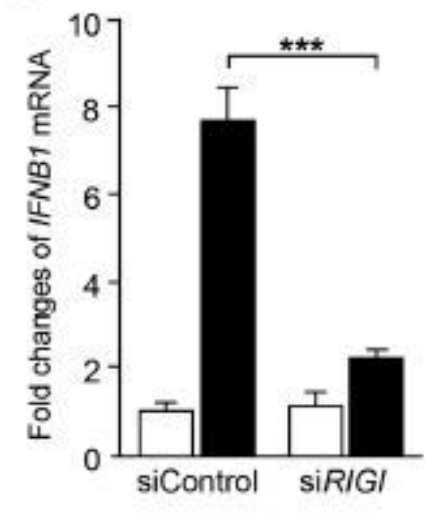

b

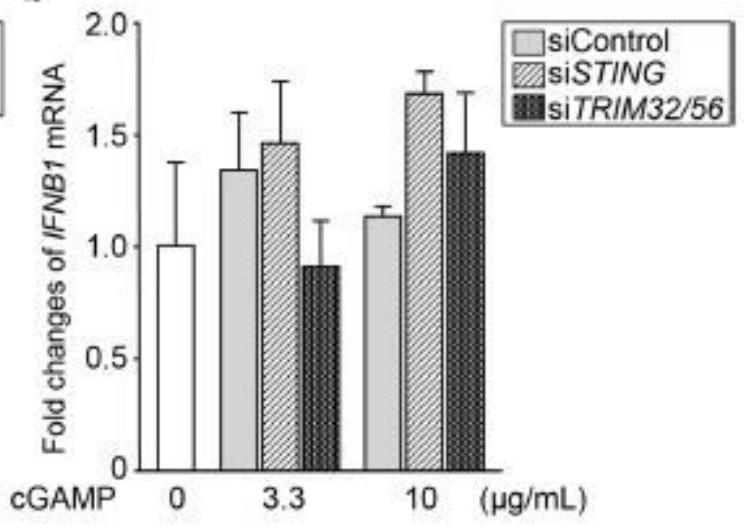

d

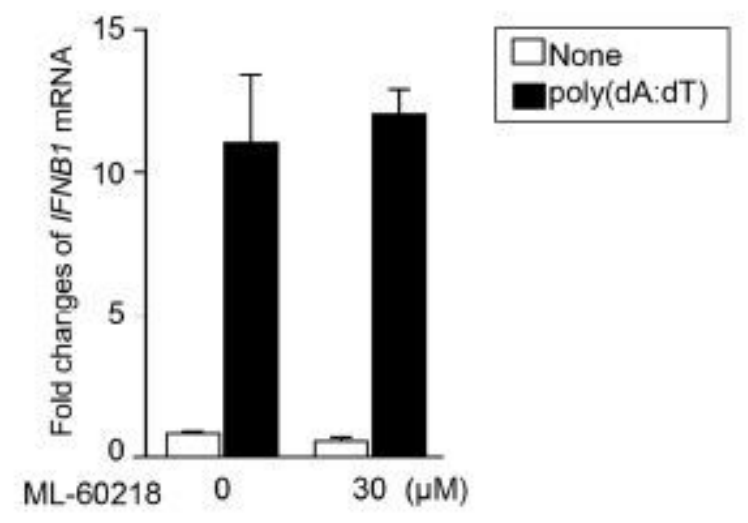

\section{Figure 4}

RIG-I but not CGAMP or STING played a role in IFNB1 upregulation. (a) IFNB1 expression was determined after cells were treated with a control or STING siRNA for $6 \mathrm{~h}$ and stimulated with poly(dA:dT) for an additional 6 h. IFNB1 expression increased after STING knockdown $(n=8, P<0.001)$. (b) Cells were treated with the indicated siRNAs for $6 \mathrm{~h}$ and then with cGAMP for $16 \mathrm{~h}$. IFNB1 mRNA expression did not increased after incubation with either 3.3 or $10 \mu \mathrm{g} / \mathrm{mL}$ cGAMP, using any of the three siRNAs $(n=4)$. (c) Cells were transfected with siRNA against RIG-I and stimulated with poly(dA:dT). IFNB1 expression decreased after RIG-I knockdown ( $n=4, P<0.001)$. (d) Cells were treated with the RNA polymerase III inhibitor ML- 60218 for $2 \mathrm{~h}$ and then stimulated with poly(dA:dT) for $6 \mathrm{~h}$. No change in IFNB1 expression was observed $(n=4, P=0.873)$. The bars in panels a- $d$ represent means $\pm S E M s$. ${ }^{* \star *} P<0.001$, as determined using the Tukey test for the experiments shown in panel $b$ and the Dunnett test for the experiments shown in the other panels. 
a

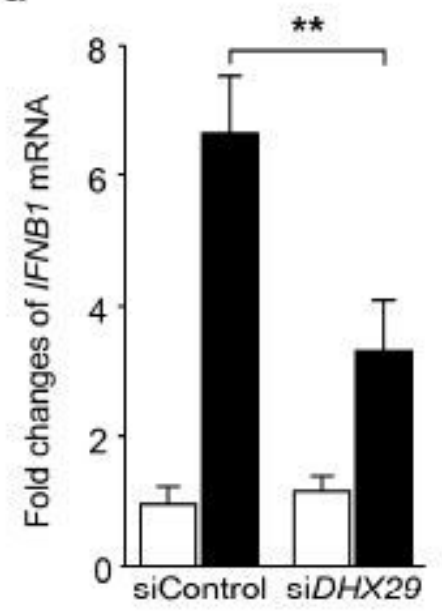

b

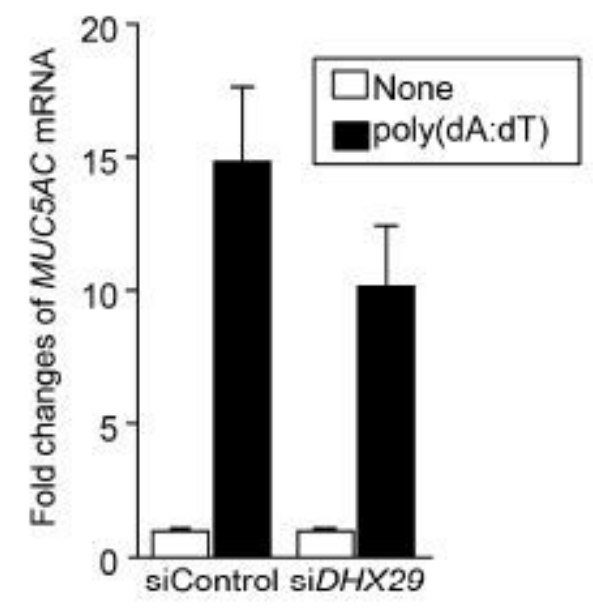

Figure 5

DHX29 participated in cytosolic DNA-induced IFNB1 expression. ( $a$ and $b$ ) Cells were treated with siRNA for $6 \mathrm{~h}$ and stimulated with poly(dA:dT) for $6 \mathrm{~h}$. The mRNA expression levels of (a) IFNB1 and (b) MUC5AC were determined by RT-PCR. IFNB1 was inhibited by DHX29 knockdown $(n=12, P=0.003)(a)$, whereas a significant difference was not observed for MUC5AC expression (b) $(n=12, P=0.270)$. The error bars represent means \pm SEMs. ${ }^{*} \mathrm{P}<0.01$, as determined using the Tukey test.

a

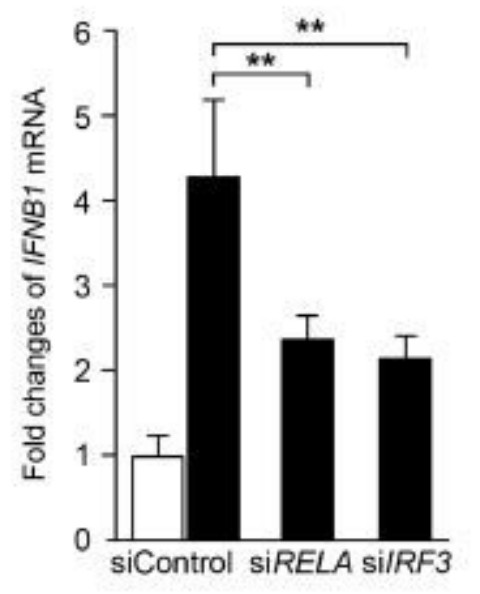

b

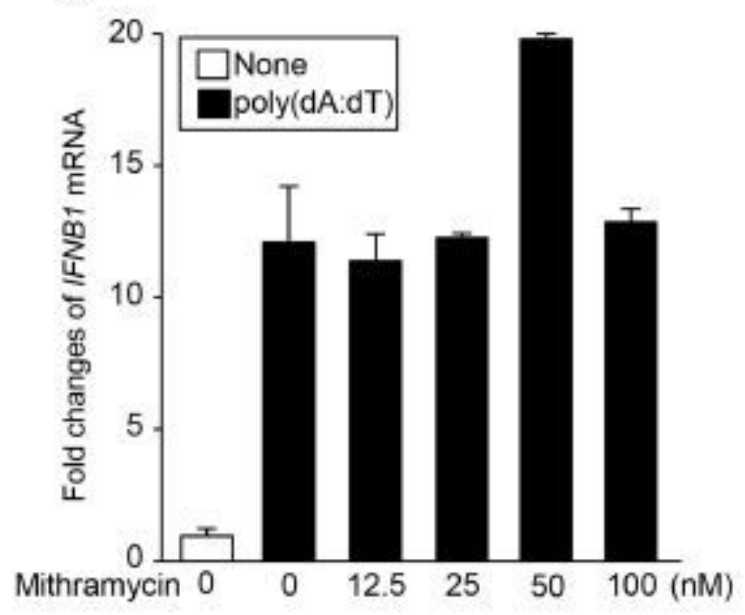

Figure 6 
NF-KB and IRF3, but not SP1, were involved in IFNB1 mRNA expression. (a) Cells were treated with siRNA for $6 \mathrm{~h}$ and then stimulated with poly(dA:dT) for $6 \mathrm{~h}$. IFNB1 expression was suppressed by RELA knockdown $(P=0.003)$ and IRF3 knockdown $(P=0.002)(n=12)$. (b) Cells were treated with poly $(d A: d T)$ for $4.5 \mathrm{~h}$ and stimulated with the SP1 inhibitor mithramycin A for $17 \mathrm{~h}(\mathrm{n}=4)$. The error bars represent means \pm SEMs. ${ }^{*} P<0.01$, as determined using the Dunnett test.

\section{Supplementary Files}

This is a list of supplementary files associated with this preprint. Click to download.

- SupplementaryDataCombined.pdf 